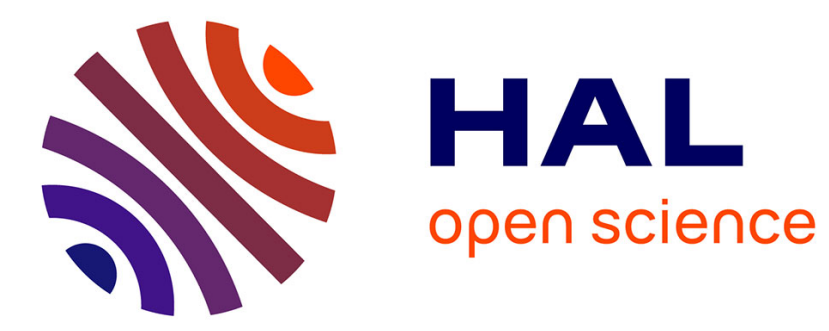

\title{
Elastic precursor attenuation in iron and steels
}

E. Shorohov, A. Gornovoi, A. Denisenko

\section{To cite this version:}

E. Shorohov, A. Gornovoi, A. Denisenko. Elastic precursor attenuation in iron and steels. Journal de Physique IV Proceedings, 1994, 04 (C8), pp.C8-409-C8-414. 10.1051/jp4:1994863 . jpa-00253423

\section{HAL Id: jpa-00253423 https://hal.science/jpa-00253423}

Submitted on 1 Jan 1994

HAL is a multi-disciplinary open access archive for the deposit and dissemination of scientific research documents, whether they are published or not. The documents may come from teaching and research institutions in France or abroad, or from public or private research centers.
L'archive ouverte pluridisciplinaire HAL, est destinée au dépôt et à la diffusion de documents scientifiques de niveau recherche, publiés ou non, émanant des établissements d'enseignement et de recherche français ou étrangers, des laboratoires publics ou privés. 


\title{
Elastic precursor attenuation in iron and steels
}

\author{
E.V. Shorohov, A.A. Gornovoi and A.A. Denisenko \\ Research Institute of Technical Physics, P.O. Box 245, Chelyabinsk-70, 454070, Russia
}

\begin{abstract}
Résumé: le phénomène d'atténuation du précurseur élastique dans le fer ARMCO et dans des aciers de différentes duretés initiales et de différents taux d'impuretés a été étudieé expérimentalement. On montre l'inflience de la microstructure initiale des matériaux sur l'amplitude, la forme et le temps de montée du précurseur élastique. La description des résultats expérimentaux est réalisée par un modèle statistique et cinétique. La résultats obtenus montrent que la principale atténuation des contraintes a lieu dans la zone proche a la surface de la surface de l'échantillon.
\end{abstract}

\begin{abstract}
: the phenomenon of the elastic precursor attenuation in armco-iron and steels with different initial hardness and addition composition is experimentally investigated. The influence of the initial defect structure in materials on the precursor amplitude, the front form and the rate of the stress drop in the precursor is noted. The experimental results description is given by means of the statistical and kinetic model. From the obtained estimations it follows that the main stress drop in the precursor takes place in the zone close to the superficial zone of the sample.
\end{abstract}

\section{INTRODUCTION}

The reaction of many metals on the shock-wave action with stress in the range from some GPa up to some tens of $\mathrm{GPa}$ is often of the plasto-elastic nature. In the wave front the elastic precursor and the plastic waves can be distinguished. As the elastic precursor passes deeply into the sample from the surface of loading, its amplitude is decreased [1]. The investigation of this phenomenon is of interest for making clear the physical reasons specifying the stresses relaxation for the extremely short times of the dynamic action. For describing the precursor attenuation, the dislocation models [2] are involved. The dependence of the stress drop rate on the initial number of defects is noted. However, the difference between the measured amplitude and the predicted one is so great that, in the theory, it is necessary to assume dislocation densities to be more than by three orders higher than it corresponds to reality, but in the zone close to the superficial one of loading - even higher. The attenuation investigation presents here a problem since for the resolution of the changes taking place at the precursor front some measurements should be performed in nanosecond and picosecond ranges. Therefore, one of the methods for investigating the relaxation phenomena in thin layers remains the construction of the physically non-contradictory extrapolation dependencies. 
In the given work, the elastic precursor attenuation was investigated in iron and in number of steels differing in various addition composition and initial thermal treatment. The description of the experimental results is given by using the model taking into account the statistical and kinetic nature of the solids strength [3], and conclusions about the attenuation character in the zone close to the superficial zone of loading are made.

\section{EXPERIMENTAL DETALS}

In experiments the samples of armco-iron, $40 \mathrm{H}$ steels with different initial hardness HRC $15 \div 24$ units, HRC $33 \div 41$ units, HRC $52 \div 54$ units, 30HGSA and $20 \mathrm{HN} 3 \mathrm{~A}$ steels have been used. The shock waves registration was realized according to the optical level technique [3]. The experimental arrangement and the typical chronogram are given in Fig. 1.
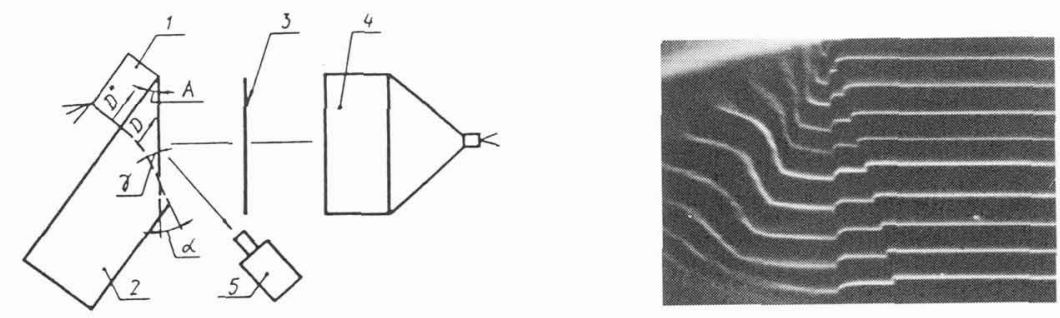

Figure 1

Experimental set-up scheme and typical photo-chronogram.

1 - explosive (HE) h=1 mm - $40 \mathrm{~mm} ; 2$ - investigated sample; 3 - system of point light sources - raster; 4 - explosive source of light. 5 - high speed camera.

The registration technique was based on the principle of the free surface displacement following when shock waves appear on this surface. For this purpose the images of light sources are built on the reflecting surface of the sample. Wave and mass velocities are determined by the surface motion character. Loading is realized by the sliding detonation of the explosives. By using the wedge-shaped geometry of the sample it is possible to follow in detail the changes in the elastic precursor amplitude depending on depth and to determine the plastic wave parameters. The two-wave structure of the waves as well as the tree-wave one was registered depending on the type and the thickness of the explosive. The three-wave configuration was connected with $\alpha \rightarrow \varepsilon$ polymorphous transformation. In all investigated metals the precursor attenuation has been noted.

\section{RESULTS AND DISCUSSION}

The influence of heat treatment of $40 \mathrm{H}$ steel and alloy additions in steels is displayed in the precursor front structure. It is quantitatively shown in Fig. 2. In $40 \mathrm{H}$ steel hardened up to HRC $52 \div 54$ units the wave front is prolonged with distinctly expressed dispersion of sound velocities that indicates a great anisotropy of yield points obtained in the material under hardening up to HRC $52 \div 54$ units. In armco-iron it was noted the occurrence of the "yield tooth". The Hugoniot elastic limit is determined according to the higher and lower values. The alloyed steel fronts are more steep with a slight rising at the foot of a plastic wave. 


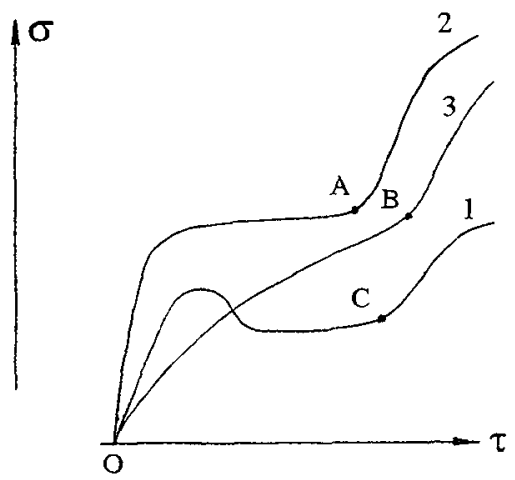

Figure 2

Quantitative picture of the precursor front structure in the investigated materials. 1 - armco-iron; 2 20HN3A steel, $40 \mathrm{H}$ steel with HRC equal to $15 \div$ 24 units and HRC equal to $41 \div 33$ units, 30HGSA steel; 3 - $40 \mathrm{H}$ steel with HRC equal to $52 \div 54$ units.

In Fig. 3, 4 the results of measurements are presented for these materials in the stress-time coordinates $\left(\sigma^{\mathrm{H}}-\tau\right)$, where $\tau$ - time interval between the successive arrival of the elastic and plastic wave fronts at the given point of the sample. Time $\tau$ is determined by the formula

$$
\tau=L\left(c_{l}-C_{s}\right) / c_{l} C_{s},
$$

where $L$ - length of the way passed by an elastic wave up to the given point of the sample from the loading surface, $C_{l}$ - elastic precursor velocity, $C_{s}$ - plastic wave velocity. In [4] this time is called the "precursor life time". On the experimental profiles this interval corresponds to time intervals O-A,O-B, O-C ( Fig. 2).

The availability of the precursor attenuation allows to assume the microplastic flow occurrence in the early stages of shock action. For describing the kinetics of this phenomenon, equation obtained in [3] is used:

$$
\sigma^{\mathrm{H}}=\frac{1-\mu}{1-2 \mu} E\left(\frac{V a}{c_{l}^{3} \tau^{3}}\right)^{1 /\left(\alpha_{u}+1\right)}\left(\varepsilon_{*}-\frac{\alpha R T}{c_{p}} \ln \frac{\tau}{\tau_{\mathrm{o}}}\right)
$$

where :

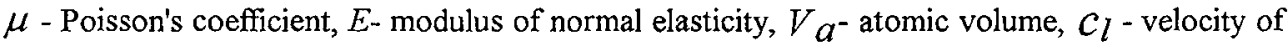
a longitudinal elastic wave, $\varepsilon_{*}=0.2$-critical deformation of the solid microvolume which corresponds to the realization of the theoretical yield limit value for the crystal lattice when the deformation is uniaxial, $\alpha$ - linear expansion coefficient, $\mathcal{C}_{p}$ - specific heat, $R$ - universal gas constant, $T$ - absolute temperature of solid, $\tau_{O}$ - period of thermal vibrations for the crystal lattice atoms, $\alpha_{u}$ - homogeneity coefficient (structural parameter) of two-parameter Veibull's distribution function. reasons:

From (1) it follows that the rate of the precursor amplitude decrease is determined by two 
1. heat fluctuations taken into account in (1) through the member $\frac{\alpha R T}{c_{p}} \ln \frac{\tau}{\tau_{o}}$

2. increase of probability for appearing structure defects being capable to give rise to microplastic deformation in the volume $c_{l}^{3} \tau^{3}$ with growth of $\tau$.

The results of the description (1) are presented in Fig. 3, 4.

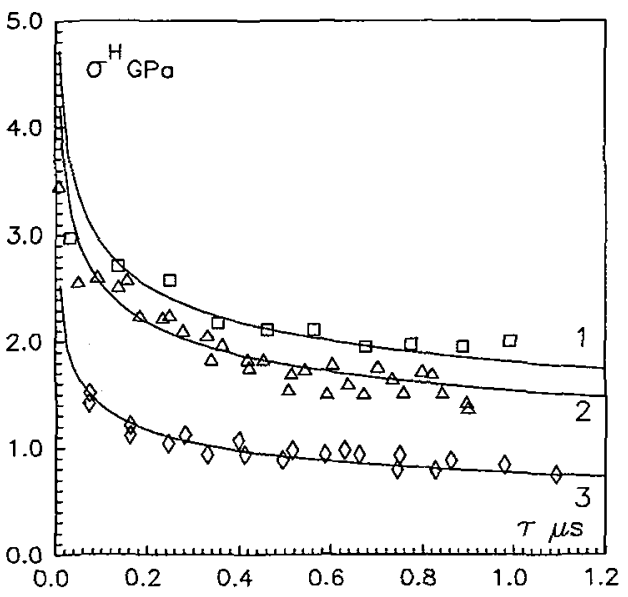

Figure 3

Attenuation of elastic precursor in the investigated materials.

1 - 30HGSA steel; 2 - 20HN3A steel;

3 - armco-iron; - dependence calculated according to formula (1).

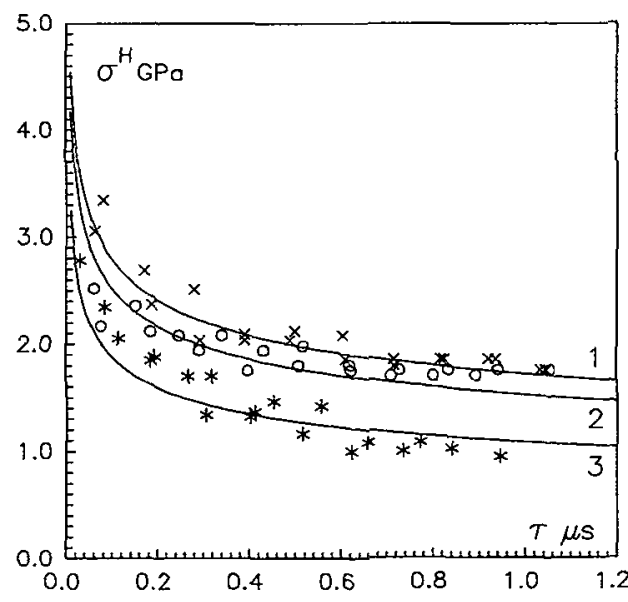

Figure 4

Influence of the initial hardness on the character of elastic precursor attenuation in $40 \mathrm{H}$ steel.

1 - HRC equal to $33 \div 41$ units; $2 \mathrm{HRC}$ equal to $15 \div 24$ units; 3 - HRC equal to $52 \div 54$ units.

The model parameters are given in Table 1. For all investigated materials the following values of the parameters were used: $\rho=7.85 \mathrm{Mg} / \mathrm{m}^{3}$ (density of sample); $\mu=0.27 ; T=293 \mathrm{~K} ; \alpha=12.110^{-6} \mathrm{~K}^{-}$ 1; $c_{l}=5.95 \div 6.05 \mathrm{~km} / \mathrm{s} ; V_{a}=55.847 \cdot 10^{-6} \mathrm{~m}^{3} / \mathrm{mol}$. It is noted that computation and experimental stress results are in close agreement within $10 \%$. 
Table 1: Model Parameters

\begin{tabular}{|c|c|c|c|}
\hline Materials & $\mathrm{E}(\mathrm{GPa})$ & $\mathrm{C}_{\mathrm{p}}(\mathrm{j} / \mathrm{kg} \cdot \mathrm{K})$ & $\alpha_{u}$ \\
\hline Armco-iron & 200 & 456 & 10.93 \\
\hline $30 \mathrm{HGSA}$ & 198 & 434 & 13.88 \\
\hline $20 \mathrm{HN} 3 \mathrm{~A}$ & 210 & 670 & 13.21 \\
\hline $40 \mathrm{H}(\mathrm{HRC} 15 \div 24)$ & 200 & 522 & 13.18 \\
\hline $40 \mathrm{H}(\mathrm{HRC} 33 \div 41)$ & 200 & 522 & 13.66 \\
\hline $40 \mathrm{H}(\mathrm{HRC} 52 \div 54)$ & 200 & 522 & 11.96 \\
\hline
\end{tabular}

The influence of the initial defect structure in the materials on the precursor amplitude and its attenuation is followed in the experimentally investigated region of iron and steel loading stresses $\sigma<25$ GPa. It is visually demonstrated on $40 \mathrm{H}$ steel as an example with different initial hardnesses, see Fig. 4 . As compared with armco-iron, the Hugoniot elastic limit is higher in steels and has its proper character of attenuation.

In Fig. 5 extrapolation dependencies are given for of the materials investigated in the range of small times on the assumption of constant elastic modules.

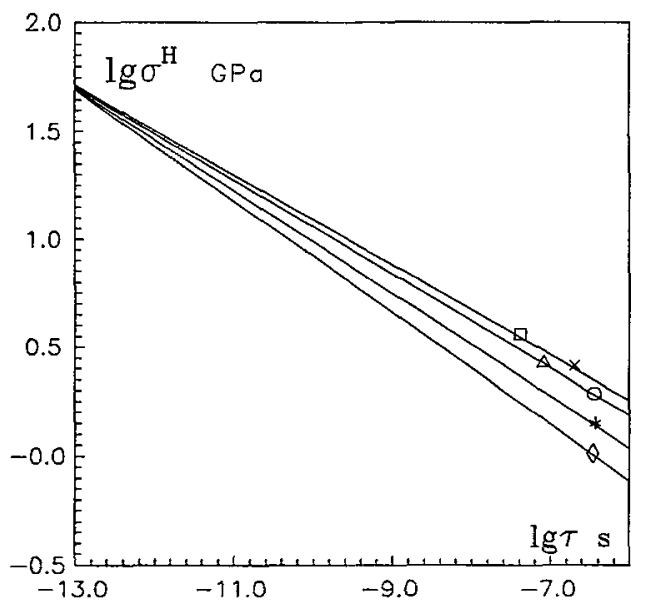

Figure 5

Extrapolation dependence of Hugoniot elastic limit on the "precursor life-time".

Within the framework of the adopted model formalities it follows that at $\tau \sim 10^{-13}$ s the ultimate elastic stress for iron and steels tends to $50 \mathrm{GPa}$. It is natural to assume that the dissipation of the precursor elastic energy begins in the source which is greater than the atomic volume $\left(\tau \sim 10^{-12} \div 10^{-13} \mathrm{~s}\right)$. Proceeding from this assumption the theoretical shear strength of iron can be estimated to be equal to $10 \div 15 \mathrm{GPa}$ that is not in contrast with available experimental data obtained for the thread-like crystals of iron. 


\section{REFERENCES}

[1]. Ivanov A.G., Novikov S.A., Sinitzin V.A., Russ.J. Solid-State Physics, v. 1(1963), 269-278.

[2]. Clifton R.J., Markenscoff X., J. Mech. Phys. Solid, v. 29, 3(1981), 227-251.

[3]. Gornovoi A.A., Kozlov E.A., Muzyrya A.K., Shorohov E.V., Physics of Combustion and Explosion, 1(1989), 142-144.

[4]. Vorob'ev A.I., Gornovoi A.A, Novikov S.A., Physics of Combastion and Explosion , 4 (1988), 109-114. 